\title{
The Usefulness of Muscle Biopsy in Initial Diagnostic Evaluation of Mitochondrial Encephalomyopathy, Lactic Acidosis, and Stroke-Like Episodes
}

\author{
Min-Seong Baek ${ }^{1 *}$, Se Hoon Kim²*, and Young-Mock Lee ${ }^{1}$ \\ Departments of ${ }^{1}$ Pediatrics and ${ }^{2}$ Pathology, Yonsei University College of Medicine, Seoul, Korea.
}

\begin{abstract}
Purpose: The disease entity mitochondrial encephalomyopathy, lactic acidosis, and stroke-like episodes (MELAS) is characterized by an early onset of stroke-like episodes. MELAS is the most dominant subtype of mitochondrial disease. Molecular genetic testing is important in the diagnosis of MELAS. The mitochondrial DNA (mtDNA) 3243A $>$ G mutation is found in $80 \%$ of MELAS patients. Nevertheless, molecular analysis alone may be insufficient to diagnose MELAS because of mtDNA heteroplasmy. This study aimed to evaluate whether muscle biopsy is useful in MELAS patients as an initial diagnostic evaluation method.

Materials and Methods: The medical records of patients who were diagnosed with MELAS at the Department of Pediatrics of Gangnam Severance Hospital between January 2006 and January 2017 were reviewed. The study population included 12 patients. They were divided into two subgroups according to whether the results of muscle pathology were in accordance with mitochondrial diseases. Clinical variables, diagnostic evaluations, and clinical outcomes were compared between the two groups.

Results: Of the 12 patients, seven were muscle pathology-positive for mitochondrial disease. No statistically significant difference in clinical data was observed between the groups that were muscle pathology-positive and muscle pathology-negative for mtDNA 3243A >G mutation. Additionally, the patients with weakness as the initial symptom were all muscle pathology-positive.

Conclusion: The usefulness of muscle biopsy appears to be limited to an initial confirmative diagnostic evaluation of MELAS. Muscle biopsy can provide some information in MELAS patients with weakness not confirmed by genetic testing.
\end{abstract}

Key Words: MELAS, muscle biopsy, genetic diagnosis, morphological diagnosis

\section{INTRODUCTION}

Mitochondria are organelles in cells that perform a variety of cellular metabolic functions, including the generation of most cellular energy in the form of adenosine triphosphate. ${ }^{1}$ Mitochondrial disease is a clinically heterogeneous group of dis-

\footnotetext{
Received: May 30, 2018 Revised: October 21, 2018

Accepted: October 23, 2018

Corresponding author: Young-Mock Lee, MD, PhD, Department of Pediatrics, Gangnam Severance Hospital, Yonsei University College of Medicine, 211 Eonjuro, Gangnam-gu, Seoul 06273, Korea.

Tel: 82-2-2019-3350, Fax: 82-2-2019-4881, E-mail: ymleemd@yuhs.ac

*Min-Seong Baek and Se Hoon Kim contributed equally to this work.

-The authors have no potential conflicts of interest to disclose.

(C) Copyright: Yonsei University College of Medicine 2019

This is an Open Access article distributed under the terms of the Creative Commons Attribution Non-Commercial License (https://creativecommons.org/licenses/ by-nc/4.0) which permits unrestricted non-commercial use, distribution, and reproduction in any medium, provided the original work is properly cited.
}

eases, in which mitochondrial dysfunction is caused by several mutations of mitochondrial or nuclear DNA. ${ }^{2}$

The disease mitochondrial encephalomyopathy, lactic acidosis and stroke-like episodes (MELAS) is characterized by early onset of stroke-like episodes. MELAS syndrome is the most dominant subtype of mitochondrial disease. ${ }^{3,4}$ It is one of the most frequent maternally inherited mitochondrial disorders and has been shown to be associated with an $A>G$ transition at position 3243 of the tRNA ${ }^{\text {LeU(UUR) }}$ gene. ${ }^{5,6}$

The diagnosis of MELAS is based on a combination of clinical findings, biochemical testing, muscle pathology, and molecular genetic testing. Typically, a blood sample is initially tested as part of the diagnostic evaluation in patients clinically suspected with MELAS. ${ }^{7}$ Meanwhile, the usefulness of muscle biopsy in terms of initial diagnostic evaluation remains unknown. This study aimed to study the usefulness of muscle biopsy in MELAS patients with mitochondrial DNA (mtDNA) $3243 \mathrm{~A}>\mathrm{G}$ mutation as an initial diagnostic tool. 


\section{MATERIALS AND METHODS}

\section{Patients}

The medical records of patients who were diagnosed with MELAS based on the diagnostic criteria of Yatsuga, et al. ${ }^{2}$ at the Department of Pediatrics of Gangnam Severance Hospital between January 2006 and January 2017 were reviewed. Patients without mtDNA mutation were excluded from the analysis. The Institutional Review Board of Gangnam Severance Hospital in Seoul, Korea approved all procedures (3-2015-0156). Informed consent was obtained, and all methods were performed in accordance with the relevant guidelines and ethics board regulations.

\section{Study design}

The study population was divided into two subgroups according to whether the results of muscle pathology were in accordance with mitochondrial diseases or $\operatorname{not}(n=7$ vs. $n=5$, respectively). Clinical variables, diagnostic evaluations, and clinical outcomes were compared between the two groups (Fig. 1).

\section{Clinical characteristics, diagnostic investigations, and clinical outcomes for MELAS}

Clinical data on age at onset of the first symptom, nature of the first symptom, age at diagnosis, period from the first symptoms to the last visit, and organ involvement were collected. Laboratory test results were also obtained, including serum lactic acid levels. The degree of serum lactic acidosis was defined as mild, moderate, or severe if the increase was more than the normal reference values at less than two-, three-, or more than three-fold, respectively. All patients were tested for genetic mutations involved in MELAS, including mtDNA 3243A>G mutation. Muscle biopsies from the quadriceps muscle, with which histologic, light microscopic, and electron microscopic examinations were performed. Specific findings

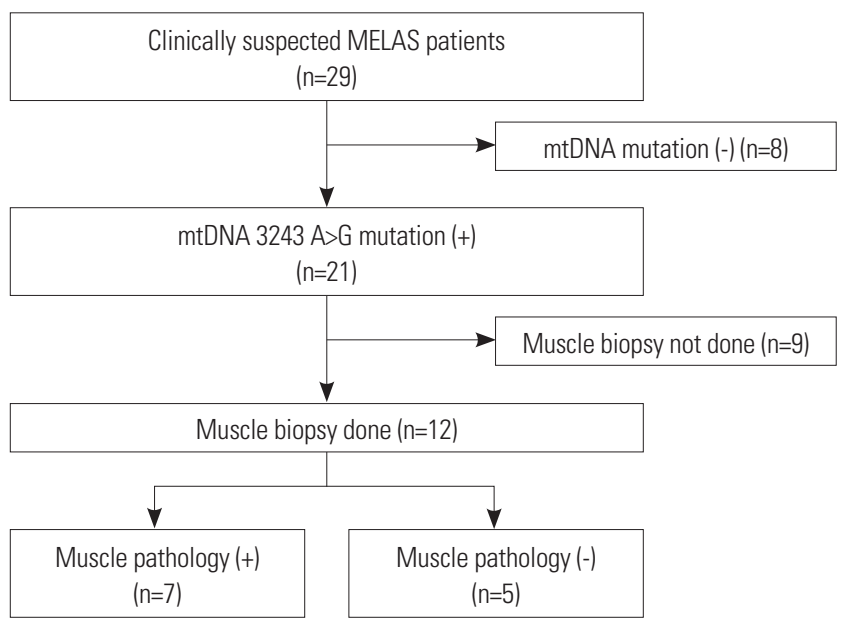

Fig. 1. Flowchart of patient inclusion. MELAS, mitochondrial encephalomyopathy, lactic acidosis, and stroke-like episodes; mtDNA, mitochondrial DNA. for mitochondrial diseases under a light microscope were defined as the presence of ragged red fibers (RRF) or abnormal staining. Abnormal mitochondrial morphology was defined under the electron microscope as pleoconia and megaconia. Biochemical enzyme assay in the muscle was also performed to evaluate mitochondrial respiratory chain (MRC) enzyme activity. MRC complex defect was defined as a residual enzyme activity $<10 \%$ of the reference value. Data from magnetic resonance imaging and magnetic resonance spectroscopy study were also collected.

The clinical severity of patients was defined as follows: normal, ambulatory, and independent for daily activities; mild, ambulatory, or independent for daily activities; moderate, wheelchair-bound, or partially dependent for daily activities; and severe, bedridden, totally dependent for daily activities, or expired.

\section{Statistical analysis}

All analyses were performed using SPSS version 20.0 (IBM Corp., Armonk, NY, USA). Descriptive statistics were used including the median and range. Differences between subgroups were evaluated using the Mann-Whitney U test (Wilcoxon rank sum test) and Fisher's exacts test. $p$ values $<0.05$ were considered statistically significant.

\section{RESULTS}

\section{Patient characteristics and clinical features at the last visit}

A total of 21 patients was recruited in this study. Among them, 12 were male and nine were female (Table 1). The initial presenting symptoms varied, with seizures ( 9 of $21,42.9 \%$ ) being the most common, followed by mental change (4 patients, $19 \%$ ), weakness (4 patients, 19\%), visual disturbance, and ataxia. The mean age of the first symptom onset was $14.9 \pm 9.7$ years. Central nervous system involvement was found in all patients, and various organs were affected as shown in Table 1. Besides central nervous system involvement, the ear was the most commonly involved organ in $16(76.2 \%)$ patients. The majority of patients had multiple organ involvement including the gastrointestinal tract, endocrine system, eyes, and heart $(71.4,71.4,66.7$, and $57.1 \%$, respectively).

\section{Diagnostic evaluations}

All patients were diagnosed with MELAS, which was confirmed by genetic testing, and they were all positive for mtDNA 3243A > G mutation. Increased serum lactic acid levels were observed in all patients. Magnetic resonance images of the brain revealed a variety of abnormal findings, including atrophy or abnormal signal intensities in different areas, and almost all patients (20 of 21 patients) had evidence of infarction at the time of the study. Magnetic resonance spectroscopy 
study data were obtained in 19 patients. The presence of lactate peak was observed in 16 patients $(84.2 \%)$. Muscle biopsy was performed in 12 patients (57.1\%). Table 2 shows the abnormal

Table 1. Characteristics and Clinical Features at the Last Visit

\begin{tabular}{|c|c|}
\hline Characteristics and clinical features & Total $(n=21)$ \\
\hline Sex (male:female) (\%) & $12(57.1): 9(42.9)$ \\
\hline Age at onset of the first symptom (yr) & $14.9 \pm 9.7(0.6-37.3)$ \\
\hline Age at onset of the first seizure (yr) & $15.6 \pm 9.6(0.6-37.3)$ \\
\hline $\begin{array}{l}\text { Time interval from first clinical presentation } \\
\text { to the last visit (yr) }\end{array}$ & $7.2 \pm 4.2(1.4-14.4)$ \\
\hline \multicolumn{2}{|l|}{ Initial presenting symptoms, $\mathrm{n}(\%)$} \\
\hline Seizure & $9(42.9)$ \\
\hline Mental change & $4(19.0)$ \\
\hline Weakness & $4(19.0)$ \\
\hline Visual disturbance & $3(14.3)$ \\
\hline Ataxia & $1(4.8)$ \\
\hline \multicolumn{2}{|l|}{ Clinical features at the last visit, $\mathrm{n}(\%)$} \\
\hline Central nervous system & $21(100)$ \\
\hline \multicolumn{2}{|l|}{ Respiratory system } \\
\hline Frequent pneumonia & $4(19.0)$ \\
\hline $\mathrm{O}_{2}$ dependency & $1(4.8)$ \\
\hline Normal & $16(76.2)$ \\
\hline \multicolumn{2}{|l|}{ Renal system } \\
\hline Abnormal kidney findings of ultrasonography & $6(28.6)$ \\
\hline Nephrotic syndrome or proteinuria & $4(19.0)$ \\
\hline Normal & $11(52.4)$ \\
\hline \multicolumn{2}{|l|}{ Gastrointestinal system } \\
\hline Gastroesophageal reflux disease & $11(52.3)$ \\
\hline Enteral tube feeding & $9(42.9)$ \\
\hline Diffuse liver disease & $6(28.6)$ \\
\hline Gallbladder polyp or stone & $4(19.0)$ \\
\hline Pancreatitis & $2(9.5)$ \\
\hline Normal & $6(28.6)$ \\
\hline \multicolumn{2}{|l|}{ Heart } \\
\hline Cardiomyopathy & $10(47.6)$ \\
\hline Wolff-Parkinson-White syndrome & $6(28.6)$ \\
\hline Normal & $9(42.9)$ \\
\hline \multicolumn{2}{|l|}{ Eye } \\
\hline Optic atrophy & $8(38.1)$ \\
\hline Retinopathy & $4(19.0)$ \\
\hline Visual field defect & $2(9.5)$ \\
\hline Ophthalmoplegia & $1(4.8)$ \\
\hline Normal & $7(33.3)$ \\
\hline \multicolumn{2}{|l|}{ Ear } \\
\hline Hearing impairment & $14(66.7)$ \\
\hline Hearing loss & $2(9.5)$ \\
\hline Normal & $5(23.8)$ \\
\hline \multicolumn{2}{|l|}{ Endocrine system } \\
\hline Diabetes mellitus & $13(61.9)$ \\
\hline Osteoporosis & $4(19.0)$ \\
\hline Adrenal insufficiency & $1(4.8)$ \\
\hline Normal & $6(28.6)$ \\
\hline
\end{tabular}

findings seen under light microscopy and electron microscopy, as well as MRC enzyme activity: abnormal changes specific to mitochondrial diseases under a light microscope were

Table 2. Diagnostic Evaluations of MELAS ( $n=21$ )

\begin{tabular}{|c|c|}
\hline Evaluations & n (\%) \\
\hline Mitochondrial DNA 3243A $>$ G mutation (+) & $21(100)$ \\
\hline \multicolumn{2}{|l|}{ Serum lactic acidosis } \\
\hline Mildly increased (<2-fold) & $5(23.8)$ \\
\hline Moderately increased (2-3-fold) & $9(42.9)$ \\
\hline Severely increased ( $\geq 3$-fold) & $7(33.3)$ \\
\hline MRI obtained & $21 / 21(100)$ \\
\hline Infarction & $20(95.2)$ \\
\hline \multicolumn{2}{|l|}{ Diffuse atrophy } \\
\hline Mild & $8(38.1)$ \\
\hline Severe & $10(47.5)$ \\
\hline Cerebellar signal abnormality & $18(85.7)$ \\
\hline Basal ganglia signal abnormality & $12(57.1)$ \\
\hline Thalamus signal abnormality & $2(9.5)$ \\
\hline White matter signal abnormality & $14(66.7)$ \\
\hline Cortex signal abnormality & $20(95.2)$ \\
\hline MR spectroscopy obtained & $19 / 21(90.5)$ \\
\hline Presence of lactate peak & $16 / 19(84.2)$ \\
\hline Muscle biopsy obtained & $12 / 21(57.1)$ \\
\hline Myopathic changes (+) & $8 / 12(66.6)$ \\
\hline \multicolumn{2}{|l|}{ Light microscopy } \\
\hline Specific findings for mitochondrial diseases & $7 / 12(58.3)$ \\
\hline Nonspecific findings & $1 / 12(8.3)$ \\
\hline Normal & 4/12 (33.3) \\
\hline \multicolumn{2}{|l|}{ Electron microscopy } \\
\hline Pleoconia & $4 / 12(33.3)$ \\
\hline Megaconia & $4 / 12(33.3)$ \\
\hline Normal & $8 / 12(66.7)$ \\
\hline MRC complex enzyme assay obtained & $10(47.6)$ \\
\hline MRC complex I defect & $8 / 10(80.0)$ \\
\hline MRC complex IV defect & $1 / 10(10.0)$ \\
\hline MRC complex I and IV defect & $1 / 10(10.0)$ \\
\hline
\end{tabular}

MELAS, mitochondrial encephalomyopathy, lactic acidosis, and stroke-like episodes; MRC, mitochondrial respiratory chain.

Table 3. Clinical Outcomes at Last Visit

\begin{tabular}{lc}
\hline \multicolumn{1}{c}{ Clinical outcomes } & Total ( $\mathbf{n = 2 1 )}$ \\
\hline $\begin{array}{l}\text { Number of stroke-like episodes } \\
\text { Delayed development or mental retardation, } \mathrm{n}(\%)\end{array}$ & $3.5 \pm 2.9(0-10)$ \\
$\begin{array}{l}\text { Clinical severity at last outpatient clinic, } \mathrm{n}(\%) \\
\quad \text { Normal (ambulatory and independent for daily } \\
\text { activities) }\end{array}$ & $6(28.6)$ \\
Mild (ambulatory or independent for daily activities) & $3(14.3)$ \\
$\begin{array}{l}\text { Moderate (WC bound and/or partially dependent } \\
\text { for daily activities) }\end{array}$ & $4(19.0)$ \\
$\quad \begin{array}{l}\text { Severe (bedridden, totally dependent for daily } \\
\text { activities or expired) }\end{array}$ & $8(38.1)$ \\
\hline WC, wheelchair. &
\end{tabular}


seen in seven of the 12 patients (58.3\%); electron microscopic changes with pleoconia or megaconia were noted in four of the 12 patients (33.3\%). Biochemical enzyme assay in the muscle tissue revealed deficiency of MRC complex I in nine of 10 patients $(90 \%)$ (Table 2$)$.

Table 4. Comparison of General Characteristics and Clinical Features between Subgroups

\begin{tabular}{|c|c|c|c|}
\hline Characteristics and clinical features & Muscle pathology $(+)(n=7)$ & Muscle pathology (-) (n=5) & $p$ value \\
\hline \multicolumn{4}{|l|}{ Sex, n (\%) } \\
\hline Male & $4(57.1)$ & $3(60.0)$ & 0.689 \\
\hline Female & $3(42.9)$ & $2(40.0)$ & \\
\hline Age at onset of the first symptom (months) & $94(17-448)$ & $134(67-426)$ & 0.639 \\
\hline Age at onset of the first seizure (months) & $132(55-448)$ & $134(67-426)$ & 1.000 \\
\hline Time interval from the first clinical presentation to the last visit (months) & $109(23-137)$ & $114(25-136)$ & 0.755 \\
\hline \multicolumn{4}{|l|}{ Initial presenting symptoms, n (\%) } \\
\hline Seizure & $3(42.9)$ & $2(40.0)$ & 0.689 \\
\hline Mental change & $0(0)$ & $2(40.0)$ & 0.152 \\
\hline Weakness & $4(57.1)$ & $0(0)$ & 0.071 \\
\hline Ataxia & $0(0)$ & $1(20.0)$ & 0.417 \\
\hline \multicolumn{4}{|l|}{ Clinical features at the last visit, $\mathrm{n}(\%)$} \\
\hline Central nervous system & $7(100)$ & $5(100)$ & - \\
\hline \multicolumn{4}{|l|}{ Respiratory system } \\
\hline Frequent pneumonia & $2(28.6)$ & $1(20.0)$ & 0.636 \\
\hline Oxygen dependency & $1(14.3)$ & $0(0)$ & 0.583 \\
\hline Normal & $4(57.1)$ & $4(80.0)$ & - \\
\hline \multicolumn{4}{|l|}{ Renal system } \\
\hline Abnormal kidney findings of ultrasonography & $4(57.1)$ & $1(20.0)$ & 0.247 \\
\hline Nephrotic syndrome or proteinuria & $2(28.6)$ & $1(20.0)$ & 0.636 \\
\hline Normal & $1(14.3)$ & $3(60.0)$ & - \\
\hline \multicolumn{4}{|l|}{ Gastrointestinal system } \\
\hline Gastroesophageal reflux disease & $5(71.4)$ & $3(60.0)$ & 0.576 \\
\hline Enteral tube feeding & $4(57.1)$ & $3(60.0)$ & 0.689 \\
\hline Diffuse liver disease & $3(42.9)$ & $2(40.0)$ & 0.689 \\
\hline Gallbladder polyp or stone & $1(14.3)$ & $2(40.0)$ & 0.364 \\
\hline Pancreatitis & $1(14.3)$ & $0(0)$ & 0.583 \\
\hline Normal & $2(28.6)$ & $0(0)$ & - \\
\hline \multicolumn{4}{|l|}{ Heart } \\
\hline Cardiomyopathy & $4(57.1)$ & $3(60.0)$ & 0.576 \\
\hline Wolff-Parkinson-White syndrome & $2(28.6)$ & $2(40.0)$ & 0.636 \\
\hline Normal & $3(42.9)$ & $1(20.0)$ & - \\
\hline \multicolumn{4}{|l|}{ Eye } \\
\hline Optic atrophy & $2(28.6)$ & $2(40.0)$ & 0.576 \\
\hline Retinopathy & $3(42.9)$ & $0(0)$ & 0.159 \\
\hline Visual field defect & $0(0)$ & $1(20.0)$ & 0.417 \\
\hline Ophthalmoplegia & $1(14.3)$ & $0(0)$ & 0.583 \\
\hline Normal & $1(14.3)$ & $2(40.0)$ & - \\
\hline \multicolumn{4}{|l|}{ Ear } \\
\hline Hearing impairment & $6(85.7)$ & $4(80.0)$ & 0.682 \\
\hline Hearing loss & $1(14.3)$ & $0(0)$ & 0.583 \\
\hline Normal & $0(0)$ & $1(20.0)$ & - \\
\hline \multicolumn{4}{|l|}{ Endocrine system } \\
\hline Diabetes mellitus & $3(42.9)$ & $4(80.0)$ & 0.247 \\
\hline Osteoporosis & $2(28.6)$ & $1(20.0)$ & 0.636 \\
\hline Adrenal insufficiency & $0(0)$ & $1(20.0)$ & 0.417 \\
\hline Normal & $3(42.9)$ & $0(0)$ & - \\
\hline
\end{tabular}




\section{Clinical outcomes}

The mean time interval from the first clinical presentation to the last visit at our institute was $7.2 \pm 4.2$ years, and the number of stroke like episodes averaged during the study duration was $3.5 \pm 2.9$ (range 0 to 10 ). Of the 21 patients, 16 patients $(76.2 \%)$ exhibited delayed development or mental retardation, and 12 patients $(57.1 \%)$ had moderate to severe impairment in daily living functions. Our data showed that clinical severities were quite variable (Table 3 ).

\section{Analysis of general characteristics, clinical features, diagnostic evaluations, and clinical outcomes by subgroup}

Patients with weakness as the initial symptom demonstrated

Table 5. Comparison of Diagnostic Evaluations between Subgroups

\begin{tabular}{|c|c|c|c|}
\hline Evaluations & Muscle pathology $(+)(n=7)$ & Muscle pathology $(-)(n=5)$ & $p$ value \\
\hline Mitochondrial DNA 3243A>G mutation (+), n (\%) & $7(100)$ & $5(100)$ & - \\
\hline \multicolumn{4}{|l|}{ Serum lactic acidosis, $n(\%)$} \\
\hline Mildly increased (<2-fold) & $1(14.3)$ & $1(20.0)$ & 0.682 \\
\hline Moderately increased (2-3-fold) & $1(14.3)$ & $3(60.0)$ & 0.152 \\
\hline Severely increased ( $\geq 3$-fold) & $5(71.4)$ & $1(20.0)$ & 0.121 \\
\hline \multicolumn{4}{|l|}{ MRI obtained, $n(\%)$} \\
\hline Infarction & $6(85.7)$ & $4(80.0)$ & 0.583 \\
\hline \multicolumn{4}{|l|}{ Diffuse atrophy } \\
\hline Mild & $1(14.3)$ & $1(20.0)$ & 0.682 \\
\hline Severe & $5(71.4)$ & $4(80.0)$ & 0.636 \\
\hline Cerebellar signal abnormality & $6(85.7)$ & $4(80.0)$ & 0.682 \\
\hline Basal ganglia signal abnormality & $4(57.1)$ & $3(60.0)$ & 0.689 \\
\hline Thalamus signal abnormality & $1(14.3)$ & $1(20.0)$ & 0.682 \\
\hline White matter signal abnormality & $5(71.4)$ & $3(60.0)$ & 0.576 \\
\hline Cortex signal abnormality & $6(85.7)$ & $5(100)$ & 0.583 \\
\hline MR spectroscopy obtained, n (\%) & $7(100)$ & $4(80.0)$ & \\
\hline Presence of lactate peak & $7 / 7(100)$ & $4 / 4(100)$ & 0.417 \\
\hline Muscle biopsy obtained, n (\%) & $7(100)$ & $5(100)$ & - \\
\hline Myopathic changes (+), $n(\%)$ & $7(100)$ & $1(20.0)$ & - \\
\hline \multicolumn{4}{|l|}{ Light microscopy } \\
\hline Specific findings for mitochondrial diseases & $7(100)$ & $0(0)$ & $<0.001$ \\
\hline Nonspecific findings & $0(0)$ & $1(20.0)$ & 0.417 \\
\hline Normal & $0(0)$ & $4(80.0)$ & - \\
\hline \multicolumn{4}{|l|}{ Electron microscopy } \\
\hline Pleoconia & $4(57.1)$ & $0(0)$ & 0.071 \\
\hline Megaconia & $4(57.1)$ & $0(0)$ & 0.071 \\
\hline Normal & $3(42.9)$ & $5(100)$ & - \\
\hline MRC complex enzyme assay, n (\%) & $6(85.7)$ & $4(80.0)$ & \\
\hline MRC complex I defect & 6/6 (100) & $2 / 4(50)$ & 0.152 \\
\hline MRC complex IV defect & $0(0)$ & $1 / 4(25.0)$ & 0.417 \\
\hline MRC complex I and IV defect & $0(0)$ & $1 / 4(25.0)$ & 0.417 \\
\hline
\end{tabular}

MRC, mitochondrial respiratory chain.

Table 6. Comparison of Clinical Outcomes between Subgroups

\begin{tabular}{|c|c|c|c|}
\hline Clinical outcomes at last visit & Muscle pathology $(+)(n=7)$ & Muscle pathology $(-)(n=5)$ & $p$ value \\
\hline Number of stroke-like episodes & $4.0 \pm 3.3(1-10)$ & $4.0 \pm 2.9(2-9)$ & 0.876 \\
\hline Delayed development or mental retardation, $\mathrm{n}(\%)$ & $7(100)$ & $4(80.0)$ & 0.417 \\
\hline \multicolumn{4}{|l|}{ Clinical severity at last outpatient clinic, n (\%) } \\
\hline Normal (ambulatory and independent for daily activities) & $1(14.3)$ & $1(20.0)$ & 0.682 \\
\hline Mild (ambulatory or independent for daily activities) & $0(0)$ & $1(20.0)$ & 0.417 \\
\hline Moderate (WC bound or partially dependent for daily activities) & $2(28.6)$ & $0(0)$ & 0.318 \\
\hline Severe (bedridden, totally dependent for daily activities or expired) & $4(57.1)$ & $3(60.0)$ & 0.689 \\
\hline
\end{tabular}

WC, wheelchair. 
positive muscle pathology, although the difference was statistically insignificant $(p=0.071)$. No significant trends were observed concerning general characteristics or clinical features according to muscle pathology, nor were there any significant differences in the severity of serum lactic acidosis or neuroimaging studies and organ involvement (Tables 4 and 5). Dividing the patients into subgroups according to muscle pathology, we found that differences in light microscopic changes were statistically significant, while electron microscopic changes were similar ( $p<0.001, p=0.071$, respectively). No meaningful differences were found in terms of the parameters of the number, development, and clinical severity of stroke-like episodes (Table 6).

\section{DISCUSSION}

Most of the current diagnostic criteria on mitochondrial disease were developed prior to the recent expansion of molecular genetic knowledge. ${ }^{8,9}$ These criteria are based on combinations of clinical, laboratory, pathologic, biochemical, and genetic findings. ${ }^{10}$ Given the complexity of mitochondrial diseases, their clinical manifestations are extremely heterogeneous, and the various combinations of organ involvement have led to defining mitochondrial syndromes according to the presentations thereof: some are well known for their acronyms, such as MELAS and myoclonic epilepsy with RRF. ${ }^{1}$ However, with outstanding accuracy, molecular diagnosis is gaining popularity, and with further development in diagnostic technology, muscle biopsy has generally come to be considered less useful in MELAS patients confirmed by genetic testing. Our study is unique and meaningful because few studies have sought to assess the usefulness of muscle biopsy in mitochondrial diseases, such as MELAS.

MELAS syndrome was first described in 1984 by Pavlakis, et al. ${ }^{4}$ Later, Hirano, et al. ${ }^{11}$ defined the three almost invariant criteria of MELAS: 1) stroke-like episode before the age of 40 years; 2) encephalopathy characterized by seizures, dementia, or both; and 3) lactic acidosis, presence of RRFs, or both. The diagnosis is confirmed if at least two of the following criteria were also present: 1) normal early development, 2) recurrent headaches, and 3) recurrent vomiting episodes. Recently, the MELAS study committee in Japan published other diagnostic criteria by which the diagnosis is considered definitive with at least two category A criteria (headaches with vomiting, seizures, hemiplegia, cortical blindness, and acute focal lesions in neuroimaging) and two category B criteria (high plasma or cerebrospinal fluid lactate, mitochondrial abnormalities in muscle biopsy, and a MELAS-related gene mutation). ${ }^{6}$ Molecular genetic testing is also important in the diagnosis of MELAS. The mtDNA $3243 \mathrm{~A}>\mathrm{G}$ mutation in the MT-TL1 gene encoding tRNA ${ }^{\mathrm{Leu}(\mathrm{UUR})}$ is found in $80 \%$ of MELAS patients. ${ }^{5,12}$ Additional mtDNA mutations have been shown to be associat- ed with MELAS, such as the MT-TL1 pathogenic variants (mitochondrial DNA $3271 \mathrm{~T}>\mathrm{C}$ and mitochondrial DNA $3252 \mathrm{~A}>\mathrm{G}$ mutations). ${ }^{13}$ Currently, over $30 \mathrm{mtDNA}$ gene mutations have been found to be associated with this syndrome (http://www. ncbi.nlm.nih.gov/omim/540000). Our data were consistent with previous studies in terms of prevalence of the mtDNA $3243 \mathrm{~A}>\mathrm{G}$ mutation. ${ }^{2}$ Molecular genetic testing was performed in all patients, and they were all (100\%) positive for mtDNA $3243 \mathrm{~A}>\mathrm{G}$ mutation. No other mutations were noted. The results of the present study correspond with an earlier study that reported that the primary considerable and common gene is mtDNA $3243 \mathrm{~A}>\mathrm{G}$ mutation. The mtDNA 3243A $>\mathrm{G}$ mutation in the MT-TL1 gene has a wide phenotypic spectrum, including MELAS, chronic progressive external ophthalmoplegia, maternally inherited deafness and diabetes, and Leigh syndrome. Other reported features include isolated myopathy, cardiomyopathy, seizures, migraine, ataxia, cognitive impairment, bowel dysmotility, and short stature. ${ }^{14,15}$ The extreme variability in the clinical phenotype is due to the proportion of mutated mtDNA or the number of wild-type mtDNA within tissues. ${ }^{16,17}$ Detection of mtDNA point mutation without quantification alone has been generally accepted to be insufficient in the diagnosis of MELAS because of mtDNA heteroplasmy. The heteroplasmy of mtDNA makes the detection of mtDNA point mutation alone and without quantification insufficient to diagnose MELAS.

Before the development of newer molecular genetic testing, muscle biopsy was thought to be the best method to obtain accurate diagnosis of mitochondrial diseases, MELAS in particular. The diagnosis of MELAS is often confirmed by the presence of RRF on succinate dehydrogenase histochemical stain, as a result of diseased mitochondrial aggregates in the subsarcolemmal areas of muscle fibers. ${ }^{10,18,19}$ Muscle biopsy also provides muscle tissue samples for morphological, biochemical, and molecular studies. In the current study, no statistically significant difference was observed between MELAS patient harboring $3243 \mathrm{~A}>\mathrm{G}$ point mutation who were positive for muscle pathology and those who were negative for muscle pathology. On the basis of this finding, we deemed the usefulness of muscle biopsy to be limited at initial confirmative diagnosis of MELAS. Additionally, the patients with weakness as the initial symptom of MELAS were all positive for muscle pathology. While it is assumed that muscle pathology can provide some information to MELAS patients with weakness, no statistically significant relationship was found between the groups that were positive for muscle pathology and negative for muscle pathology ( $p=0.071)$. Nevertheless, these findings may reflect the difficulty of obtaining a statistical correlation because of the limited number of patients in each subgroup. Moreover, myopathy has long been recognized and well described in MELAS and several other mitochondrial diseases. ${ }^{18}$ In a prospective cohort of MELAS patients in Japan, of 96 patients, 36 (37.5\%) patients had muscle weakness at onset, and 40 (41.7\%) 
experienced muscle weakness over the entire course. ${ }^{2}$ The importance of muscle pathology in a patient suspected with MELAS syndrome should not be overlooked, particularly in a patient whose predominant clinical symptoms include muscle weakness. $^{3}$

MELAS patients harboring point mutation involve a high frequency of RRF. ${ }^{20}$ However, no studies investigating the usefulness of muscle biopsy in MELAS patients diagnosed by molecular analysis have been conducted. Previous studies have reported that the accumulation of mitochondria in muscle fibers, which were composed of typical RRF, is found in up to $97 \%$ of MELAS patients. ${ }^{20,21}$ Nevertheless, several points should be considered in regards to the limitations of muscle biopsy. The procedure is invasive and requires sedation when dealing with children. On occasion, the pathologist is only able to conclude that the specimen provides findings consistent with an unspecified myopathy. This result may occur for a variety of reasons, including cases where the obtained tissue may not have been taken from a disease-fulminant region or the volume of muscle tissue is not enough. ${ }^{22}$ Moreover, a normal reference value of muscle tissue based on age still remains unknown. ${ }^{10,19}$ Notwithstanding, muscle biopsy has been performed in the routine analysis for mitochondrial disease when the diagnosis cannot be confirmed with genetic testing. ${ }^{10}$

This study was retrospective in nature, and it has some limitations. Because of disease rarity, the size of the study population was small, which may imply that the results are not sufficient for making generalized interpretations. From the results, the usefulness of muscle biopsy was shown to be limited in making the initial confirmative diagnosis of MELAS. Muscle biopsy was not able to provide additional information on MELAS patients when already diagnosed through genetic testing. However, muscle biopsy could provide some information if genetic testing cannot confirm a diagnosis in clinically suspected MELAS patients with weakness, which may be a symptom of myopathy. In short, though a genetic test should be the first choice to diagnose MELAS, muscle biopsy should be considered as an additional choice in clinically suspected MELAS patient with weakness not confirmed by genetic testing. In order to provide a more generalized guideline, studies on larger numbers of patients are needed to better delineate the usefulness of muscle biopsy in MELAS. Mitochondrial disease is heterogeneous in general, and each of the mitochondrial syndromes tend to display their own specific clinical manifestations. These characteristics warrant continuous study, and whether previous diagnostic tools are in fact the best methods for each specific type of syndrome needs to be verified.

\section{ACKNOWLEDGEMENTS}

This research was supported by a grant from the Korea Health Technology R\&D Project through the Korea Health Industry Development Institute (KHIDI), funded by the Ministry of Health
\&Welfare, Republic of Korea (grant number: HI16C0673).

\section{ORCID iDs}

Min-Seong Baek https://orcid.org/0000-0002-7132-362X

Se Hoon Kim https://orcid.org/0000-0001-7516-7372

Young-Mock Lee https://orcid.org/0000-0002-5838-249X

\section{REFERENCES}

1. Zeviani M, Di Donato S. Mitochondrial disorders. Brain 2004;127 (Pt 10):2153-72.

2. Yatsuga S, Povalko N, Nishioka J, Katayama K, Kakimoto N, Matsuishi T, et al. MELAS: a nationwide prospective cohort study of 96 patients in Japan. Biochim Biophys Acta 2012;1820:619-24.

3. Goto Y, Horai S, Matsuoka T, Koga Y, Nihei K, Kobayashi M, et al. Mitochondrial myopathy, encephalopathy, lactic acidosis, and stroke-like episodes (MELAS): a correlative study of the clinical features and mitochondrial DNA mutation. Neurology 1992;42(3 Pt 1):545-50.

4. Pavlakis SG, Phillips PC, DiMauro S, De Vivo DC, Rowland LP. Mitochondrial myopathy, encephalopathy, lactic acidosis, and strokelike episodes: a distinctive clinical syndrome. Ann Neurol 1984;16:481-8.

5. Goto Y, Nonaka I, Horai S. A mutation in the tRNA(Leu)(UUR) gene associated with the MELAS subgroup of mitochondrial encephalomyopathies. Nature 1990;348:651-3.

6. El-Hattab AW, Adesina AM, Jones J, Scaglia F. MELAS syndrome: clinical manifestations, pathogenesis, and treatment options. Mol Genet Metab 2015;116:4-12.

7. Kisler JE, Whittaker RG, McFarland R. Mitochondrial diseases in childhood: a clinical approach to investigation and management. Dev Med Child Neurol 2010;52:422-33.

8. Haas RH, Parikh S, Falk MJ, Saneto RP, Wolf NI, Darin N, et al. Mitochondrial disease: a practical approach for primary care physicians. Pediatrics 2007;120:1326-33.

9. Koenig MK. Presentation and diagnosis of mitochondrial disorders in children. Pediatr Neurol 2008;38:305-13.

10. Parikh S, Goldstein A, Koenig MK, Scaglia F, Enns GM, Saneto R, et al. Diagnosis and management of mitochondrial disease: a consensus statement from the Mitochondrial Medicine Society. Genet Med 2015;17:689-701.

11. Hirano M, Ricci E, Koenigsberger MR, Defendini R, Pavlakis SG, DeVivo DC, et al. Melas: an original case and clinical criteria for diagnosis. Neuromuscul Disord 1992;2:125-35.

12. Parsons T, Weimer L, Engelstad K, Linker A, Battista V, Wei Y, et al. Autonomic symptoms in carriers of the m.3243A $>$ G mitochondrial DNA mutation. Arch Neurol 2010;67:976-9.

13. Morten KJ, Cooper JM, Brown GK, Lake BD, Pike D, Poulton J. A new point mutation associated with mitochondrial encephalomyopathy. Hum Mol Genet 1993;2:2081-7.

14. Moraes CT, Ciacci F, Silvestri G, Shanske S, Sciacco M, Hirano M, et al. Atypical clinical presentations associated with the MELAS mutation at position 3243 of human mitochondrial DNA. Neuromuscul Disord 1993;3:43-50.

15. Nesbitt V, Pitceathly RD, Turnbull DM, Taylor RW, Sweeney MG, Mudanohwo EE, et al. The UK MRC Mitochondrial Disease Patient Cohort Study: clinical phenotypes associated with the m.3243A $>\mathrm{G}$ mutation--implications for diagnosis and management. J Neurol Neurosurg Psychiatry 2013;84:936-8.

16. Uusimaa J, Moilanen JS, Vainionpää L, Tapanainen P, Lindholm P, Nuutinen $\mathrm{M}$, et al. Prevalence, segregation, and phenotype of the 
mitochondrial DNA 3243A $>$ G mutation in children. Ann Neurol 2007;62:278-87.

17. Manwaring N, Jones MM, Wang JJ, Rochtchina E, Howard C, Mitchell P, et al. Population prevalence of the MELAS A3243G mutation. Mitochondrion 2007;7:230-3.

18. Sproule DM, Kaufmann P. Mitochondrial encephalopathy, lactic acidosis, and strokelike episodes: basic concepts, clinical phenotype, and therapeutic management of MELAS syndrome. Ann N Y Acad Sci 2008;1142:133-58.

19. Rollins S, Prayson RA, McMahon JT, Cohen BH. Diagnostic yield muscle biopsy in patients with clinical evidence of mitochondrial cytopathy. Am J Clin Pathol 2001;116:326-30.

20. Goto Y. Clinical features of MELAS and mitochondrial DNA mutations. Muscle Nerve Suppl 1995;3:S107-12.

21. Lorenzoni PJ, Scola RH, Kay CS, Arndt RC, Freund AA, Bruck I, et al. MELAS: clinical features, muscle biopsy and molecular genetics. Arq Neuropsiquiatr 2009;67:668-76.

22. Joyce NC, Oskarsson B, Jin LW. Muscle biopsy evaluation in neuromuscular disorders. Phys Med Rehabil Clin N Am 2012;23:609-31. 